\title{
Factors Associated with Self-Reported 14 or More Activity Limitation Days among Adults in the United States
}

\author{
Gemechu B. Gerbi, MSc, $\mathbf{P h D}^{1,2}$; Marc-Edwin Saint-Louis, $\mathrm{MPH}^{2}$; Elaine Archie- \\ Booker, EdD, RN, ICPS ${ }^{1,2}$; Mechelle D. Claridy, MPH $^{2}$; Stephanie Miles-Richardson, \\ DVM, PhD $^{1,2}$ \\ ${ }^{1}$ Department of Community Health and Preventive Medicine, Morehouse School of Medicine, \\ Atlanta, Georgia, USA \\ ${ }^{2}$ Master of Public Health Program, Morehouse School of Medicine, Atlanta, Georgia, USA
}

\begin{abstract}
:
Objective: It is estimated that 41 million American adults 18 and older experience poor physical or mental health which limits their ability to engage in their daily activities. The objective of this study was to assess the prevalence of and factors associated with $\geq 1$ 4activity limitation days (ALD) due to poor physical or mental health as self-reported by persons aged 18 years and over in the United States (U.S).
\end{abstract}

Methods: Using the 2012 Behavioral Risk Factors Surveillance System (BRFSS), persons over the age of 18 in the U.S. were examined to assess the prevalence of and factors associated with $\geq 14 A L D$ due to poor physical or mental health. The BRFSS is administered on a continuous basis by telephone using random-digit dial sampling methods. A clustering sample design was used to account for differences in the probability of selection and nonresponse in order to accurately derive US and state-based population estimates. The design consists of a probability sample of all households with telephones in the state. Analyses were conducted using SAS 9.2.

Results: Of the 104,257 participants included in the analyses, 40\% reported having $\geq 14$ ALD due to poor physical or mental health. After adjusting for demographic and socioeconomic factors, males (AOR1.17, 95\% CI: 1.14-1.21), those with high school or less education (AOR: 1.42, 95\% CI: 1.37-1.21), those who were separated (AOR: 1.23; 95\% CI=1.14-1.32), divorced (AOR: 1.10; 95\% CI=1.06-1.15), those from the Southern Black Belt States (AOR1.14, 95\% CI: 1.10-1.20), and those from the remainder of the Southern region of the U.S. (AOR1.14, 95\% CI: 1.08-1.21) were significantly more likely to report $\geq 14 A L D$ due to poor physical or mental health.

Conclusion: The prevalence of $\geq 14 A L D$ due to poor physical or mental health among the study population was associated with sociodemographic and region of residence factors. These findings highlight the need for prevention strategies specifically for populations who might be more at risk for ALD due to social determinants of health.

Keywords: ALD, physical or mental health, United States

\section{INTRODUCTION}

According to Healthy People 2020, limitation of activity refers to the reduction ina person's ability to perform his or her usual activities over a period of time. The ability to participate in daily activities is an important measure of the overall health and well-being of the population[1]. Studies have shown a positive association between self-reported physical activity and health-related quality of life (HRQOL)[2].In fact, a sedentary lifestyle is known to increase the risk of developing chronic health conditions such as cardiovascular diseases, hypertension, type 2 diabetes mellitus, colon and breast cancers, osteoporosis, depression, and backaches [2-4]. As such, the Centers for Disease Control and Prevention (CDC) monitors surveillance of health-related quality of life (HRQOL), defined as "perceived physical and mental health over time"[5] . In a previous study, 5.5 percent of adults ages 18 to 44 and 7.3 percent of children under age 18 experience limitation in their daily activities[1]. As the population ages, activity limitation becomes greater. The epidemic of chronic diseases is linked to population aging[6]and physical inactivity is a primary cause of many chronic diseases[7]. It has been noted that roughly 32.6 percent of non-institutionalized adults age 65 and older in the US experience 
limitations of activities of daily living such as self-care, work, or recreation[8].For example, arthritis and activity limitation due to joint symptoms contributes to limitations which leads to dependency and subsequently decreases QOL[9]. It is also estimated that 41 million American adults 18 and older experience poor physical or mental health that limit their daily activity[10]. Since psychological distress may contribute to further impairment, screening and treatment are recommended for mental conditions that occur in persons with chronic diseases who report activity limitation days (ALD)[11]. This study assesses the prevalence of and factors associated with self-reported $\geq 14$ ALD due to poor physical or mental health among persons aged 18 years and over in the United States.

\section{METHODS}

\subsection{Data Source}

We analyzed data from the 2012 Behavioral Risk Factor Surveillance System (BRFSS)[12, 13].The BRFSS is a collaborative project between all of the 50 states in the U.S., the District of Columbia, three U.S. territories (Puerto Rico, Guam, and the US Virgin Islands) and the Centers for Disease Control and Prevention (CDC). It is designed to measure behavioral risk factors for noninstitutionalized adults who reside in the U.S. and its territories.

\subsection{Sampling and Setting}

The BRFSS is nationally coordinated by the CDC and conducted by state health departments in all 50 states and the District of Columbia. BRFSS is used to collect prevalence data among adult U.S. residents regarding their risk behaviors and preventive health practices that can affect their health status. Respondent data are forwarded to CDC to be aggregated for each state.

The BRFSS questionnaire is administered on a continuous basis by telephone using random-digit dial sampling methods. The design consists of a probability sample of all households with telephones in the state. A clustering sample design was used to account for differences in the probability of selection and non-response in order to accurately derive US and state-based population estimates. In 2012, more than 450,000 interviews were conducted through the BRFSS. Annual surveys consist of a core set of questions about various health topics; such health-related risk behaviors, chronic health conditions, and use of preventive services. Sociodemographic data collected include age, sex, race/ethnicity, marital status, education, employment, and household income. The BRFSS data are publicly available and used for health policy development and advocacy at both the national and state levels.

\subsection{Measures}

All measures in this study were based on self-reported data obtained from the 2012 BRFSS.

\section{Independent Variables or Demographic Characteristics}

Participants responded to questions about their gender, race or ethnicity, age, education, income, marital status, and region of residence. The term "Southern Black Belt States" and "South remainder" were used to describe sub-regions of the Southern region of the U.S.

\section{Dependent Variable}

The ALD question is one of four core health-related QOL measures that have been monitored by states using the BRFSS. Response to the following question was used to determine the prevalence of ALD among persons with poor physical or mental health: "During the past 30 days, for about how many days did poor physical or mental health keep you from doing your usual activities, such as selfcare, work or recreation?" The response options were " _ _ number of days," "none," "don't know/not sure," or "refused." Only those records with "the number of days" were included in the analysis. The items measured in days were dichotomized at a cut-off value of $\geq 14$ days of poor health in the past month versus $\leq 13[14]$.

\section{Statistical Analysis}

We used univariate analysis to calculate relative frequencies for gender, race or ethnicity, age, education, income, marital status, and region of residence. A bivariate analysis was utilized to conduct an initial assessment of the factors independently associated with $\geq 14$ ALD due to poor physical or mental health. All of the variables that had achieved $p \leq 0.05$ in the bivariate analysis were included in 
the multivariable logistic regression model. Adjusted odds ratios (AORs) and 95\% confidence intervals (95\% CIs) were obtained. Bivariate and multivariable analyses excluded persons with responses that were missing or recorded as "don't know/not sure" or "refused." A 2 sided $p$ value of $\leq$ 0.05 was considered to indicate statistically significant. All statistical analyses were performed using SAS version 9.2[15].

\section{RESUlts}

Table 1 displays the socio-demographic characteristics and region of residence identified in the study population. Of the 104,257 individuals who responded to the survey question: "During the past 30 days, for about how many days did poor physical or mental health keep you from doing your usual activities, such as self-care, work or recreation?", 62, $512(60 \%)$ reported $\leq 13$ days of activity limitation due to poor physical or mental health in the past 30 days, while $41,745(40 \%)$ reported $\geq$ 14 days of activity limitation.. The majority of the respondents who reported $\geq 14$ days of activity limitation were females (63\%), non-Hispanic Whites (72\%), between the ages of 45-64 (49\%). Included in this group of respondents were those who had a high school education or less (53\%), had annual household incomes less than $\$ 25,000$ (60\%), were married (41\%), and were from the Southern region of the U.S. (35\%).

Table1. Number ${ }^{a}$ and percentage for the recent activity limitation days, due to poor physical or mental health in the past 30 days, by select characteristics: 2012 BRFSS, United States

\begin{tabular}{|c|c|c|}
\hline \multirow{4}{*}{$\begin{array}{l}\text { Select Characteristics } \\
\text { Overall }\end{array}$} & \multicolumn{2}{|c|}{$\begin{array}{l}\begin{array}{l}\text { Poor Activity Limitation Days } \\
(\mathrm{N}=104,257)\end{array} \\
\end{array}$} \\
\hline & 1-13 days & 14-30 days \\
\hline & n $(\%)$ & n (\%) \\
\hline & $62512(60)$ & $41745(40)$ \\
\hline \multicolumn{3}{|l|}{ Gender } \\
\hline Male & $22427(36)$ & $15247(37)$ \\
\hline Female & $40085(64)$ & $26498(63)$ \\
\hline Total & $62512(100)$ & $41745(100)$ \\
\hline \multicolumn{3}{|l|}{ Race } \\
\hline Non-Hispanic White & $25261(72)$ & 17401(72) \\
\hline Non-Hispanic Black (AA) & $3648(11)$ & $2964(12)$ \\
\hline Hispanic or Latino & $4894(14)$ & $3195(13)$ \\
\hline Asian & $388(1)$ & $91(0.3)$ \\
\hline Native Hawaiian or Other Pacific Islander & $57(0.2)$ & $33(0.10)$ \\
\hline American Indian or Alaska Native & $673(2)$ & $639(2.6)$ \\
\hline Total & $34921(100)$ & $22759(100)$ \\
\hline \multicolumn{3}{|l|}{ Age group } \\
\hline $17-44$ & $21300(34)$ & $7290(18)$ \\
\hline $45-64$ & $25853(42)$ & $20301(49)$ \\
\hline $65-74$ & $8956(14)$ & $7541(18)$ \\
\hline 75 and above & $6034(10)$ & $6328(15)$ \\
\hline Total & $62143(100)$ & $41460(100)$ \\
\hline \multicolumn{3}{|l|}{ Level of education } \\
\hline High School or less & $21710(35)$ & $21798(53)$ \\
\hline Some College & $17809(29)$ & $11749(28)$ \\
\hline College Graduate & $22823(36)$ & $8034(19)$ \\
\hline Total & $62342(100)$ & $41581(100)$ \\
\hline \multicolumn{3}{|l|}{ Level of income } \\
\hline Less than $\$ 24,999$ & $19003(35)$ & $21634(60)$ \\
\hline$\$ 25,000$ to $\$ 49,999$ & $14078(25)$ & $7768(22)$ \\
\hline$\$ 50,000$ to $\$ 74,999$ & $8436(15)$ & $3009(8)$ \\
\hline$\$ 75,000$ or more & $13969(25)$ & $3466(10)$ \\
\hline Total & $55486(100)$ & $35877(100)$ \\
\hline \multicolumn{3}{|l|}{ Marital Status } \\
\hline Married & $30083(50)$ & $16457(41)$ \\
\hline Never Married & $11872(20)$ & $5777(14)$ \\
\hline Divorced & $9632(16)$ & $9397(23)$ \\
\hline
\end{tabular}


Gemechu B. Gerbi et al.

\begin{tabular}{|l|l|l|}
\hline \hline Separated & $1723(3)$ & $1854(5)$ \\
\hline Widowed & $6626(11)$ & $7005(17)$ \\
\hline Total & $\mathbf{5 9 9 3 6 ( 1 0 0 )}$ & $\mathbf{4 0 4 9 0 ( 1 0 0 )}$ \\
\hline Region of residence & & \\
\hline South Black Belt States ${ }^{\mathrm{b}}$ & $11615(18)$ & $9720(24)$ \\
\hline South Remainder ${ }^{c}$ & $5947(10)$ & $4551(11)$ \\
\hline Midwest & $13992(23)$ & $8863(22)$ \\
\hline Northeast & $13644(22)$ & $8431(20)$ \\
\hline West & $16437(27)$ & $9556(23)$ \\
\hline Total & $\mathbf{6 1 6 3 5 ( 1 0 0 )}$ & $\mathbf{4 1 1 2 1 ( 1 0 0 )}$ \\
\hline
\end{tabular}

${ }^{a}$ Frequency may vary due to missing values

${ }^{b}$ South Black Belt States: Virginia, North Carolina, South Carolina, Georgia, Florida, Alabama, Mississippi, Tennessee, Louisiana, Arkansas, Texas

${ }^{c}$ South Remainder: Delaware, District of Columbia, Maryland, West Virginia, Kentucky, Oklahoma

Table 2 presents the results of multivariable logistic regression analysis for socio-demographic (gender, race or ethnicity, age, education, income, marital status, and region of residence) variables regressed on self-reported days of activity limitation due to poor physical or mental health in the past 30 days. After adjusting for the aforementioned socio-demographic and region of residence variables and comparing to those who reported $\leq 13$ days of activity limitation due to poor physical or mental health, male (AOR1.17, 95\% CI: 1.14-1.21), respondents who were 45-64 years of age (AOR: 2.13, 95\% CI: 2.06-2.23), those who were 65-74 years of age (AOR: 2.10, 95\% CI: 2.00-2.21), respondents aged $\geq 75$ years(AOR: 2.31, 95\% CI: 2.20-2.24), being American Indian or Alaska Native $(\mathrm{AOR}=1.15 ; 95 \% \mathrm{CI}=1.01,1.30)$, those with some college education (AOR: 1.42, 95\% CI: 1.37,1.48), those with high school or less education (AOR: 1.42 , 95\% CI: $1.37-1.21$ ), those with a $<\$ 75,000$ annual household income, those who were separated (AOR: 1.23; 95\% CI=1.14-1.32), divorced (AOR: 1.10; 95\% CI=1.06-1.15), and those from the Southern region of the U.S. (Southern Black Belt States and the Southern Remainder) were more likely to report $\geq 14$ days of activity limitations due to poor physical or mental health in the last 30 days. As compared to non-Hispanic Whites, nonHispanic Blacks or African Americans were less likely to report $\geq 14$ days of activity limitations $(\mathrm{AOR}=0.87 ; 95 \% \mathrm{CI}=0.82,0.93)$, as were Hispanic or Latino $(\mathrm{AOR}=0.84 ; 95 \% \mathrm{CI}=0.79,0.89)$, and Asian $(\mathrm{AOR}=0.56 ; 95 \% \mathrm{CI}=0.43,0.72)$.

Table2.Multivariable analyses for self-reported $\geq 14$ activity limitation days, due to poor physical or mental health in the last 30 days, by select characteristics: 2012 BRFSS, United States

\begin{tabular}{|l|l|}
\hline Characteristics & $\begin{array}{l}\left.\text { Adjusted } \mathbf{O R}^{\mathbf{a}} \mathbf{( 9 5 \%} \mathbf{C I}\right)^{\mathbf{b}} \text { for self-reported } \geq 14 \text { activity } \\
\text { limitation days }\end{array}$ \\
\hline Gender & \\
\hline Female & 1.00 \\
\hline Male & $1.17(1.14-1.21)^{\mathrm{e}}$ \\
\hline Race & \\
\hline Non-Hispanic Black (AA) & $0.87(0.82-0.93)^{\mathrm{e}}$ \\
\hline Non-Hispanic White & 1.00 \\
\hline Hispanic or Latino & $0.84(0.79-0.89)^{\mathrm{e}}$ \\
\hline Asian & $0.56(0.43-0.72)^{\mathrm{e}}$ \\
\hline Native Hawaiian or Other Pacific Islander & $1.18(0.72-1.91)$ \\
\hline American Indian or Alaska Native & $1.15(1.01-1.30)^{\mathrm{c}}$ \\
\hline Age group & \\
\hline 18-44 & 1.00 \\
\hline $45-64$ & $2.13(2.06-2.23)^{\mathrm{e}}$ \\
\hline 65-74 & $2.10(2.00-2.21)^{\mathrm{e}}$ \\
\hline 75 and above & $2.31(2.20-2.44)^{\mathrm{e}}$ \\
\hline Level of education & \\
\hline High School or less & $1.72(1.65-1.79)^{\mathrm{e}}$ \\
\hline Some College & $1.42(1.37-1.48)^{\mathrm{e}}$ \\
\hline College Graduate & 1.00 \\
\hline Annual Household Income & \\
\hline Less than \$24,999 & $3.61(3.43-3.80)^{\mathrm{e}}$ \\
\hline \$25,000 to \$49,99 & $1.86(1.77-1.96)^{\mathrm{e}}$ \\
\hline
\end{tabular}


Factors Associated with Self-Reported 14 or More Activity Limitation Days among Adults in the United States

\begin{tabular}{|l|l|}
\hline \hline$\$ 50,000$ to $\$ 74,99$ & $1.33(1.26-1.41)^{\mathrm{e}}$ \\
\hline$\$ 75,000$ or more & 1.00 \\
\hline Marital Status & \\
\hline Never Married & $0.77(0.73-0.80)^{\mathrm{e}}$ \\
\hline Married & 1.00 \\
\hline Divorced & $1.10(1.06-1,15)^{\mathrm{e}}$ \\
\hline Separated & $1.23(1.14-1.32)^{\mathrm{e}}$ \\
\hline Widowed & $0.99(0.94-1.04)$ \\
\hline Region of residence $^{\mathrm{t}}$ & \\
\hline South Black Belt States & \\
\hline South Remainder & $1.14(1.10-1.20)^{\mathrm{e}}$ \\
\hline Midwest $^{\mathrm{f}}$ & $1.14(1.08-1.21)^{\mathrm{e}}$ \\
\hline Northeast & $0.94(0.90-0.98)^{\mathrm{d}}$ \\
\hline West & 1.00 \\
\hline
\end{tabular}

${ }^{a}$ Odds Ratio

${ }^{b}$ Confidence Interval;

${ }^{c} p<0.05$

${ }^{d} p<0.01$

${ }^{e} p<0.0001$

${ }^{f}$ South Black Belt States: Virginia, North Carolina, South Carolina, Georgia, Florida, Alabama, Mississippi, Tennessee, Louisiana, Arkansas, Texas

${ }^{g}$ South Remainder: Delaware, District of Columbia, Maryland, West Virginia, Kentucky, Oklahoma

\section{DISCUSSION}

Persons 60 years and older are increasing worldwide; aging is likely to be the next global public health challenge $[16,17]$. In the U.S., poor physical or mental health and their related ALD will require public health attention and health systems strategies to address the needs of older adults[17], especially given the epidemiologic transition from acute illness to chronic disease [2]. As the population ages and chronic disease ensues, disabling conditions such as arthritis, chronic joint symptoms, and other causes for ALD become more likely[18]. Thus, continuous monitoring of the HRQOL, developed by the CDC, complements clinical research and practice and helps public health agencies to assess, protect and promote public health[2].

Our findings show that forty percent of the 2012 BRFSS survey participants reported $\geq 14$ days of ALD due to poor physical or mental health. Of particular importance is how self-reported ALD varied within this study population. Consistent with previous studies, advancing age and marital status were associated with an increased likelihood of $\geq 14$ ALD, regardless of demographic and geographic factors[2, 19-22]Specifically, one study shows that older adults and those who were separated, widowed, or divorced were considerably more likely to experience limitations in their activities[21]. Another study found, however, when controlling for age and education, gender and race were most predictive of ALD although marital status was also important[23]. Differences in the prevalence of chronic disease in African American women were believed to account for this finding [23, 24]. With respect to level of income and educational attainment, previous studies have also shown that those with a lower level of income and educational attainment are more likely to report $\geq 14$ ALD as compared to those of higher socioeconomic status [19, 25, 26]. Our study used a national representative sample to confirm these significant findings.

Our findings also reveal that respondents from the Southern region of the U.S. were more likely to report $\geq 14$ ALD as compared respondents from Northeast. Other studies have also shown regional variations in HRQOL of older adults, particularly in the southern U.S.[25, 27].This is not surprising, especially when considering the regional differences in the distribution of high blood pressure, stroke, diabetes, and other chronic diseases in the southeastern U.S.[25].In other words, longer days of activity limitation cannot only be seen in isolation from the individual's demographic and socio economic status, but place of residence also interacts and influences self-reported $\geq 14$ ALD. This finding suggests an avenue for further investigation and suggests resources for physical and mental health interventions for ALD should be allocated for specific regions and populations. Such targeted 
approaches are critical, as the number of people with chronic conditions is projected to increase over the next several decades[28] and the healthcare system will need to accommodate this increase. ALD is a primary contributor to most chronic diseases[7]

This study has at least two limitations to consider, regarding the data source. First, the BRFSS is a telephone-based survey and is administered to civilian, non-institutionalized adults. Therefore, the BRFSS excludes individuals without telephone service, those on military bases, and individuals in institutions. For this reason, generalizability to the entire US population is limited. Second, this study relied on self-reported information which may have introduced recall or reporting bias.

We conclude that socio-demographic factors and region of residence are associated with $\geq 14$ ALD among individuals aged $\geq 18$ years in the US as these were significant predictors of longer days of activity limitation. Longitudinal studies that incorporate quantitative and qualitative measures are essential to identify other factors associated with self-reported $\geq 14$ ALD and to identify the best targets for public health interventions and in reducing or eliminating the ALD Americans experience due to physical or mental health issues. This is especially important as we focus on ensuring the best QOL for the aging population.

\section{ACKNOWLEDGMENTS}

We would like to acknowledge the Morehouse School of Medicine Master of Public Health Program. The authors have no financial conflicts of interest to report.

\section{REFERENCES}

[1] Healthy People 2020. Available from: https://www.healthypeople.gov/2020/about/foundationhealth-measures/General-Health-Status. .

[2] Bize, R., J.A. Johnson, and R.C. Plotnik off, Physical activity level and health-related quality of life in the general adult population: a systematic review. Prev Med, 2007. 45(6): p. 401-15.

[3] Morrow, J.R., Jr., et al., A one-year follow-up to physical activity and health. A report of the Surgeon General. Am J Prev Med, 1999. 17(1): p. 24-30.

[4] U.S. Department of Health and Human Services, Physical Activity and Health: A Report of the Surgeon General. U.S. Department of Health and Human Services, Centers for Disease Control and Prevention, Atlanta, USA. 1996.

[5] Moriarty, D.G., M.M. Zack, and R. Kobau, The Centers for Disease Control and Prevention's Healthy Days Measures - population tracking of perceived physical and mental health over time. Health Qual Life Outcomes, 2003. 1: p. 37.

[6] Prince, M.J., et al., The burden of disease in older people and implications for health policy and practice. Lancet, 2015. 385(9967): p. 549-62.

[7] Booth, F.W., C.K. Roberts, and M.J. Laye, Lack of exercise is a major cause of chronic diseases. Compr Physiol, 2012. 2(2): p. 1143-211.

[8] Altman, B.M. and S.P. Gulley, Convergence and divergence: differences in disability prevalence estimates in the United States and Canada based on four health survey instruments. Soc Sci Med, 2009. 69(4): p. 543-52.

[9] Hootman, J.M. and C.G. Helmick, Projections of US prevalence of arthritis and associated activity limitations. Arthritis Rheum, 2006. 54(1): p. 226-9.

[10] Pastor, P.N., C.A. Reuben, and M. Loeb, Functional difficulties among school-aged children: United States, 2001-2007. Natl Health Stat Report, 2009(19): p. 1-23.

[11] McKnight-Eily, L.R., et al., Activity limitation, chronic disease, and comorbid serious psychological distress in U.S. adults--BRFSS 2007. Int J Public Health, 2009. 54 Suppl 1: p. 111-9.

[12] Centers for Disease, C. and Prevention, Health-related quality of life and activity limitation-eight states, 1995. MMWR Morb Mortal Wkly Rep, 1998. 47(7): p. 134-40.

[13] Verbrugge, L.M. and D.L. Patrick, Seven chronic conditions: their impact on US adults' activity levels and use of medical services. Am J Public Health, 1995. 85(2): p. 173-82.

[14] Brown, D.W., et al., Associations between recommended levels of physical activity and healthrelated quality of life. Findings from the 2001 Behavioral Risk Factor Surveillance System (BRFSS) survey. Prev Med, 2003. 37(5): p. 520-8. 
[15] SAS Institute, Cary, and NC.

[16] Chatterji, S., et al., Health, functioning, and disability in older adults--present status and future implications. Lancet, 2015. 385(9967): p. 563-75.

[17] Suzman, R., et al., Health in an ageing world--what do we know? Lancet, 2015. 385(9967): p. 484-6.

[18] Vradenburg, J.A., et al., The prevalence of arthritis and activity limitation and their predictors in Missouri. J Community Health, 2002. 27(2): p. 91-107.

[19] Campbell, V.A., et al., Surveillance for sensory impairment, activity limitation, and healthrelated quality of life among older adults--United States, 1993-1997. MMWR CDC Surveill Summ, 1999. 48(8): p. 131-56.

[20] Lafata, J.E., G.G. Koch, and W.G. Weissert, Estimating activity limitation in the noninstitutionalized population: a method for small areas. Am J Public Health, 1994. 84(11): p. 1813-7.

[21] Schoenborn, C.A., Marital status and health: United States, 1999-2002. Adv Data, 2004(351): p. $1-32$.

[22] Zahran, H.S., et al., Health-related quality of life surveillance--United States, 1993-2002. MMWR Surveill Summ, 2005. 54(4): p. 1-35.

[23] Dunlop, D.D., et al., Incidence of functional limitation in older adults: the impact of gender, race, and chronic conditions. Arch Phys Med Rehabil, 2002. 83(7): p. 964-71.

[24] Cherepanov, D., et al., Gender differences in health-related quality-of-life are partly explained by sociodemographic and socioeconomic variation between adult men and women in the US: evidence from four US nationally representative data sets. Qual Life Res, 2010. 19(8): p. 111524.

[25] Liao, Y., et al., Factors explaining excess stroke prevalence in the US Stroke Belt. Stroke, 2009. 40(10): p. 3336-41.

[26] Zimmer, Z. and J.S. House, Education, income, and functional limitation transitions among American adults: contrasting onset and progression. Int J Epidemiol, 2003. 32(6): p. 1089-97.

[27] Kachan, D., et al., Geographical variation in health-related quality of life among older US adults, 1997-2010. Prev Chronic Dis, 2014. 11: p. E110.

[28] Anderson, G. and J. Horvath, The growing burden of chronic disease in America. Public Health Rep, 2004. 119(3): p. 263-70. 